\title{
Risk factors for osteoporosis in male patients with chronic obstructive pulmonary disease in Taiwan
}

\author{
Chu-Hsu Lin ${ }^{1}$, Kai-Hua Chen ${ }^{1,2}$, Chien-Min Chen ${ }^{1,2}$, Chia-Hao Chang ${ }^{3}$, Tung-Jung Huang ${ }^{\text {Corresp., }}{ }^{4,5}$, Chia- \\ Hung Lin ${ }^{1}$ \\ ${ }^{1}$ Department of Physical Medicine and Rehabilitation, Chang Gung Memorial Hospital, Chiayi, Puzi City, Chiayi County, Taiwan \\ 2 School of Medicine, Chang Gung University, Taoyuan City, Taiwan \\ 3 Department of Nursing, Chang Gung University of Science and Technology, Chiayi Campus, Puzi City, Chiayi County, Taiwan \\ 4 Division of Thoracic Medicine, Department of Internal Medicine, Chang Gung Memorial Hospital, Yunlin, Mailiao Township, Yunlin County, Taiwan \\ 5 Department of Respiratory Care, Chang Gung University of Science and Technology, Chiayi Campus, Puzi City, Chiayi County, Taiwan \\ Corresponding Author: Tung-Jung Huang \\ Email address: donaldhuang@cgmh.org.tw
}

Objective. To investigate the risk factors for osteoporosis in male Taiwanese patients with chronic obstructive pulmonary disease (COPD). Methods. This cross-sectional study evaluated male COPD outpatients and age-matched male subjects at a regional teaching hospital. The following data were obtained and analyzed: bone mineral density of the lumbar spine and hip on dual-energy X-ray absorptiometry, demographic characteristics, questionnaire interview results, pulmonary function test results, chest posterior-anterior radiographic findings, and biochemical and high-sensitivity C-reactive protein (hs-CRP) levels. Results. Fifty-nine male COPD patients and 36 age-matched male subjects were enrolled. COPD patients had lower body mass index (BMI) $\left(23.6 \pm 4.1 \mathrm{vs} .25 .2 \pm 3.0 \mathrm{~kg} / \mathrm{m}^{2}\right)$ and higher total prevalence for osteoporosis and osteopenia than controls. Among COPD patients, patients with osteoporosis had lower BMI, body weight, waist circumference, and triglyceride level but higher hs-CRP level, and tended to have lower creatinine level. Binary logistic regression analysis for factors including age, BMI, creatinine, hs-CRP, smoking, steroid use, and forced expiratory volume in one second (FEV1) revealed that an hs-CRP level $\geq 5$ and decreased creatinine level were independent risk factors for osteoporosis in COPD patients. BMI tended to be associated with osteoporosis development, although it did not reach statistical significance, and hs-CRP was associated with COPD severity and steroid use history. Conclusion. The total prevalence of osteoporosis and osteopenia in male Taiwanese COPD patients is higher than that in age-matched male subjects and systemic inflammation is an independent risk factors for osteoporosis. Low creatinine level in COPD patients should raise the suspicion of sarcopenia and associated increased risk of osteoporosis. 
1 Title: Risk factors for osteoporosis in male patients with chronic obstructive pulmonary disease

2 in Taiwan.

3 Chu-Hsu Lin ${ }^{1}$, Kai-Hua Chen ${ }^{1,2}$, Chien-Min Chen ${ }^{1,2}$, Chia-Hao Chang ${ }^{3}$, *Tung-Jung Huang ${ }^{4,5}$,

4 Chia-Hung $\operatorname{Lin}^{1}$

$5 \quad{ }^{1}$ Department of Physical Medicine and Rehabilitation, Chang Gung Memorial Hospital, Chiayi,

$6 \quad{ }^{2}$ School of Medicine, Chang Gung University, Taoyuan, ${ }^{3}$ Department of Nursing, Chang Gung

7 University of Science and Technology, Chiayi Campus, Chiayi, ${ }^{4}$ Division of Thoracic Medicine,

8 Department of Internal Medicine, Chang Gung Memorial Hospital, Yunlin, ${ }^{5}$ Department of

9 Respiratory Care, Chang Gung University of Science and Technology, Chiayi Campus, Chiayi

10 Corresponding author: Tung-Jung Huang, Division of Thoracic Medicine, Department of Internal

11 Medicine, Chang Gung Memorial Hospital at Yunlin, No.1500, Gongye Rd., Mailiao Township,

12 Yunlin County 638, Taiwan (R.O.C.) Tel: 886-5-6915151 ext 2000, FAX: 886-5-6913222

13 E-mail: donaldhuang@cgmh.org.tw 


\section{Abstract}

15 Objective. To investigate the risk factors for osteoporosis in male Taiwanese patients with

16 chronic obstructive pulmonary disease (COPD)

17 Methods. This cross-sectional study evaluated male COPD outpatients and age-matched male

18 subjects at a regional teaching hospital. The following data were obtained and analyzed: bone

19 mineral density of the lumbar spine and hip on dual-energy X-ray absorptiometry, demographic

20 characteristics, questionnaire interview results, pulmonary function test results, chest posterior-

21 anterior radiographic findings, and biochemical and high-sensitivity C-reactive protein (hs-CRP)

22 levels.

23 Results. Fifty-nine male COPD patients and 36 age-matched male subjects were enrolled. COPD

24 patients had lower body mass index (BMI) $\left(23.6 \pm 4.1\right.$ vs. $\left.25.2 \pm 3.0 \mathrm{~kg} / \mathrm{m}^{2}\right)$ and higher total

25 prevalence for osteoporosis and osteopenia than controls. Among COPD patients, patients with

26 osteoporosis had lower BMI, body weight, waist circumference, and triglyceride level but higher

27 hs-CRP level, and tended to have lower creatinine level. Binary logistic regression analysis for

28 factors including age, BMI, creatinine, hs-CRP, smoking, steroid use, and forced expiratory

29 volume in one second (FEV1) revealed that an hs-CRP level $\geq 5$ and decreased creatinine level

30 were independent risk factors for osteoporosis in COPD patients. BMI tended to be associated

31 with osteoporosis development, although it did not reach statistical significance, and hs-CRP was 
32 associated with COPD severity and steroid use history.

33 Conclusion. The total prevalence of osteoporosis and osteopenia in male Taiwanese COPD

34 patients is higher than that in age-matched male subjects and systemic inflammation is an

35 independent risk factors for osteoporosis. Low creatinine level in COPD patients should raise the

36 suspicion of sarcopenia and associated increased risk of osteoporosis. 


\section{Introduction}

38 Chronic obstructive pulmonary disease (COPD), a major global public health issue burdening

39 health-care systems, is characterized by persistent and usually progressive airflow limitation

40 resulting from chronic inflammation of the airways and lungs (Vestbo et al., 2013). The incidence

41 and prevalence of COPD are much greater in men than in women worldwide (Afonso et al.,

42 2011). Currently, it is regarded as a heterogeneous disease with many systemic manifestations

43 and comorbidities, such as ischemic heart disease, heart failure, anemia, diabetes, skeletal muscle

44 wasting, osteoporosis, and osteoporotic fracture (Barnes \& Celli, 2009; Lee et al., 2016). It is also

45 predicted to become the third leading cause of death in the world by 2020 (Murray \& Lopez,

46 1997).

47 Osteoporosis, an important comorbidity of COPD, increases the risk of fracture, with resultant

48 pain, functional limitation, and increased mortality (Sambrook \& Cooper, 2006). Several studies

49 showed that COPD patients have a high prevalence of osteoporosis or low bone mineral density

50 (BMD), although estimates of prevalence are often underestimated and varied, depending on the

51 study methodology and case enrollment criteria (Rittayamai et al., 2012; Romme et al., 2013). A

52 recent systematic review revealed mean prevalences for osteoporosis and osteopenia in COPD

53 patients as approximately 35.1\% (9-69\%) and 38.4\% (27-67\%), respectively (Graat-Verboom et

54 al., 2009). Therefore, early detection, prevention, and treatment of osteoporosis in COPD patients 
55 is important.

56 The cause of osteoporosis in COPD patients is complex, and various risk factors are likely

57 related to the pathogenesis, such as old age (Kanis et al., 2008); tobacco smoking (Afonso et al.,

58 2011); female sex (Ekstrom et al., 2012); lower body mass index (BMI) (Graat-Verboom et al.

59 2009); physical inactivity (Silva et al., 2011); steroid use (Loke et al., 2011); lower fat-free mass

60 (Graat-Verboom et al., 2009); and systemic inflammation markers such as C-reactive protein

61 (CRP), tumor necrosis factor-alpha (TNF- $\alpha$ ), and interleukin-6 (IL-6) (Liang \& Feng, 2012;

62 Rittayamai et al., 2012). However, cumulative results of these studies are inconclusive, and the

63 definite pathogenic mechanism remains unclear. To our knowledge, data regarding risk factors in

64 Taiwan are limited, with no current research regarding the association between inflammation

65 markers or systemic inflammation and osteoporosis development (Chen et al., 2015; Lee et al.,

66 2016; Lin et al., 2015; Liu et al., 2015). Therefore, this study primarily aimed to investigate risk

67 factors for osteoporosis, particularly whether increased CRP is a predictor for osteoporosis

68 development in male Taiwanese COPD patients since it is a common and available test in the

69 hospital.

70 Materials and methods

71 Subjects and study design

72 This cross-sectional study was a sub-program of community elderly medical research program. 
73 It enrolled male COPD patients aged $\geq 45$ years from a chest outpatient clinic in a regional

74 teaching hospital in the west Chiayi County, Taiwan. Patients were clinically stable without

75 recent acute exacerbation in the previous 3 months. Age-matched male subjects were recruited

76 from participants in health examinations at local public health centers in the west Chiayi County.

77 Subjects who were willing to undergo anthropometric measurements, questionnaire interviews,

78 blood tests, chest radiography, spirometry, and BMD examination were included. Subjects with

79 rheumatic disease, bronchial asthma, or other structural lung diseases (including lung cancer,

80 bronchiectasis, and lung fibrosis) revealed by past medical history or chest radiography were

81 excluded. Written informed consent was obtained from all participants, and the study was

82 approved by the local Institutional Review Board of Chiayi Chang Gung Memorial Hospital (IRB

83 number: 96-0495B)

84 Anthropometric measurements

85 Body weight, height, and waist and hip circumferences were measured with participants

86 wearing light clothing without shoes. BMI was calculated.

\section{Questionnaire interview and medical records review}

88 All participants were interviewed using a comprehensive questionnaire. Age, medical history,

89 dietary habits, and lifestyle factors including tobacco smoking, milk or calcium supplement

90 consumption, exercise, and employment as a manual labor were recorded. If applicable, further 
91 information was collected on the amount, frequency, and duration of certain lifestyle habits.

92 Habitual milk consumption was defined as drinking $\geq 7$ glasses per week for $\geq 1$ year. Subjects

93 with habitual milk or calcium supplement consumption were considered to have a high calcium

94 intake. Habitual exercise was defined as exercising $\geq 3.5$ hours/week for $\geq 1$ year. Subjects who

95 were habitual exercisers or manual labors were defined as those with high physical activity.

96 Past medical history (including hypertension, diabetes mellitus, dyslipidemia, liver disease, and

97 renal disease) was recorded. If present, liver or renal disease was further defined.

98 Steroid use or history of acute exacerbation of COPD in the previous 3 years was determined

99 from the medical records by a physician. Steroid use was classified as (1) oral for $>6$ months

100 regardless of continuous or intermittent use, (2) inhaled for $>6$ months regardless of continuous

101 or intermittent use, (3) occasional (either oral or inhaled for $<6$ months), or (4) not used (See

102 Table 1).

103 Blood tests

104 Biochemical parameters were determined for serum blood urea nitrogen, creatinine, total

105 cholesterol, low-density lipoprotein cholesterol, high-density lipoprotein cholesterol, triglyceride,

106 glycohemoglobin (HbA1c), uric acid, homocysteine, vitamin B12, folate, and high-sensitivity

107 CRP (hs-CRP). Subjects with a CRP level above the normal reference value in the hospital ( $\geq 5$

$108 \mathrm{mg} / \mathrm{dL}$ ) were classified as the group of increased hs-CRP.

109 Lung examination 
110 All subjects underwent posterior-anterior chest radiography and spirometry. Post-bronchodilator

111 spirometry examination was performed by trained personnel using a KoKo spirometer

112 (Pulmonary Data Services, Inc., Louisville, KY, USA). The following parameters were recorded:

113 forced expiratory volume in 1 second (FEV1), FEV1 \% of predicted value (FEV1\% predicted),

114 forced vital capacity (FVC), FVC \% of predicted value (FVC\% predicted), FEV1/FVC ratio, and

115 forced expiratory flow 25-75\% (FEF 25-75\%). Chest radiography and spirometry data were

116 interpreted by a chest physician. The diagnosis and classification of the severity (stages I-IV) of

117 COPD were based on the diagnostic criteria of the Global Initiative for Chronic Obstructive Lung

118 Disease (GOLD) guidelines (Johannessen et al., 2013).

119 Bone mineral density examination

120 BMD measurements at the first to fourth lumbar vertebrae (L1-L4) and left hip (right hip if left

121 hip BMD unreadable because of conditions such as a fracture) were obtained using dual-energy

122 X-ray absorptiometry (Delphi A, QDR series; Hologic, Bedford, MA, USA).

123 According to the diagnostic criteria proposed by a World Health Organization working party

124 (Melton et al., 1993), osteoporosis and osteopenia were defined as a BMD T-score at either the

125 lumbar spine or the hip of $<-2.5$ and between -1 and -2.5 , respectively.

126 Data analysis

127 Continuous variables are presented as the mean \pm standard deviation and categorical variables

128 as the frequency and group percentage. Continuous and categorical variables were compared 
129 among groups using the independent sample $t$-test and Pearson's chi-square test or Fisher's exact

130 test, respectively. Binary logistic regression analyses were used for multivariate analysis to assess

131 which background variables were predictive of osteoporosis, and odds ratios were calculated with

132 a $95 \%$ confidence interval (CI). A $P$-value of $<0.05$ was considered significant for all tests.

133 Statistical analysis was performed with SPSS software, version 18 (SPSS, Inc., Chicago, IL, 134 USA).

\section{Results}

136 From May 2009 to August 2011, 59 male COPD patients and 36 age-matched male subjects

137 were enrolled. The data of FEV1/FVC was all above $70 \%$ in control group, on the other hand, it

138 was all below 70\% in COPD patient and the mean FEV1 of COPD patients was $1.26 \pm 0.47 \mathrm{~L}$

$139(51.0 \% \pm 18.0 \%$ predicted $)$. The mean age of the two groups was similar, but body weight and

140 BMI were lower in COPD patients. More people in COPD group had history of cigarette

141 smoking. Hip BMD was lower in COPD group. Lumbar spine BMD also tended to be lower in

142 COPD group, although it did not reach statistical significance (Table 2). Among COPD patients,

$14317(28.8 \%)$ exhibited osteoporosis and $25(42.4 \%)$ osteopenia compared with 16.7\% and 33.3\%,

144 respectively, in controls. The total prevalence of osteoporosis and osteopenia in COPD patients

145 was significant higher than that in controls by the Person's Chi-square test $(P=0.038)$. However, 
146 in multivariate binary logistic regression analysis showed that low BMI was the independent risk

147 factors of increased prevalence of osteoporosis and osteopenia and the variable COPD (COPD

148 patients versus controls) lost its statistical significance (Table 3).

149 General clinical characteristics and laboratory findings among COPD patients with and without

150 osteoporosis are shown in Table 4. Body weight, BMI, waist circumference, and triglyceride level

151 were significantly lower in the osteoporosis group. The creatinine level tended to be lower in the

152 osteoporosis group, although the statistical significance was marginal $(P=0.050)$. Patients with

153 increased hs-CRP ( $\geq 5 \mathrm{mg} / \mathrm{L}$ ) showed a high risk of osteoporosis compared with those with low

154 hs-CRP although the mean value of hs-CRP in osteoporosis group was not significantly higher

155 than that in non-osteoporosis group probably due to high standard deviation of the value.

156 Hs-CRP showed strong associations with COPD severity and pulmonary function parameters

157 (including COPD GOLD stage, FEV1, FEV1\% predicted, FVC, FVC\% predicted, FEV1/FVC,

158 and FEF 25-75\%) and steroid use. The high hs-CRP group tended to have lower BMI, although

159 there were no significant differences in age, smoking habits, and history of acute exacerbation

160 (Table 5).

161 Factors related to COPD between the osteoporosis and non-osteoporosis groups are compared

162 in Table 6. There was no significant association between osteoporosis and other variables (age,

163 COPD severity, pulmonary function test parameters, calcium intake, physical activity, cigarette 
164 smoking, frequent exacerbation of COPD, and corticosteroid use).

165 Multivariate analysis using binary logistic regression including age, BMI, creatinine, and

166 increased hs-CRP (category), still smoking (category), oral or inhaled steroid use for more than 6

167 months (category), and FEV1 showed that an hs-CRP level $\geq 5$ and decreased creatinine level

168 were independent risk factors for osteoporosis in COPD patients, with odds ratios of $58.90(95 \%$

169 CI, 2.09-1548.13) and 0.01 (95\% CI, 0.00-0.67), respectively. BMI tended to be negatively

170 associated with osteoporosis development, although statistically insignificant (Table 7). Because

171 body weight, waist circumference, and triglyceride level were strongly associated with BMI, and

172 all of the other respiratory parameters were strongly associated with FEV1 by the Pearson

173 correlation test, these factors were not included in the regression analysis.

\section{Discussion}

175 The present study revealed that the prevalences of osteoporosis and osteopenia in COPD

176 patients at a community hospital in Taiwan were $28.8 \%$ and $42.4 \%$, respectively, and the total

177 prevalence of them were higher than those in age-matched healthy controls, which was mainly

178 contributed by low BMI in COPD patients. This is in agreement with previous studies showing

179 that the risk of osteoporosis was greater in COPD patients than in healthy subjects (Graat-

180 Verboom et al., 2009; Rittayamai et al., 2012; Schnell et al., 2012). However, the prevalence of 
181 osteoporosis in our study was lower than the $40 \%$ reported in a recent study also conducted in

182 Chiayi, Taiwan (Lin et al., 2015). This may be explained by differences in subject enrollment and

183 osteoporosis definition. That study enrolled male and female COPD patients and defined

184 osteoporosis as a BMD T-score $<-2.5$ or the presence of thoracolumbar vertebral compression

185 fracture on radiography.

186 This study also revealed that increased hs-CRP, decreased creatinine, and decreased BMI and

187 its related parameters such as body weight, waist circumference, and triglyceride level were

188 associated with osteoporosis in COPD patients in univariate analysis. Multivariate analysis with

189 binary logistic regression revealed increased hs-CRP, and decreased creatinine were independent

190 risk factors for osteoporosis development in COPD patients, which implied increased systemic

191 inflammation and probably decreased muscle mass played important roles in bone loss.

192 The association between osteoporosis and COPD is multi-factorial and could be confounding

193 (Romme et al., 2013). Increasing evidence suggests an association between low BMD and

194 systemic inflammation. This may be observed in several rheumatic diseases such as systemic

195 lupus erythematosus, rheumatoid arthritis, and inflammatory bowel disease (Ali et al., 2009;

196 Lacativa \& Farias, 2010; Lane, 2006). COPD is a systemic inflammatory disease with pulmonary

197 and extra-pulmonary manifestations. A link between COPD and extra-pulmonary comorbidities

198 such as osteoporosis, atherosclerosis, skeletal muscle dysfunction, and anemia may be explained 
199 by systemic inflammation (Barnes \& Celli, 2009; Sin et al., 2006). The disease process is

200 believed to be initiated when lung tissues are exposed to environment irritants such as tobacco

201 smoke and air pollutants; subsequently, stimulated epithelial cells and macrophages release

202 inflammatory mediators, which may directly or indirectly damage the lungs and other specific

203 organs. In addition to the lungs, these mediators were detected in peripheral blood (Gan et al., 204 2004).

205 Several inflammatory markers are associated with low BMD or increased fracture risk. This

206 study revealed that increased hs-CRP was associated with osteoporosis development in COPD

207 patients after adjustment for common confounding factors including age and BMI, which is in

208 agreement with Rittayamai et al.'s study (Rittayamai et al., 2012). Another study reported that

209 TNF- $\alpha$ and IL-6 were independent predictors of low BMD. CRP also tended to be associated with

210 low BMD, although statistically insignificant (Liang \& Feng, 2012). Different case selection, for

211 example, patients with different disease severity, might have contributed to this subtle difference.

212 However, because tests to determine CRP level are relatively available and inexpensive (Buess \&

213 Ludwig, 1995), this parameter may worth considering first for detection of the existence and

214 severity of inflammation in COPD to predict disease outcome and the possibility of extra-

215 pulmonary comorbidity such as osteoporosis.

216 This study showed that increased CRP level was related to COPD severity as classified by the 
217 GOLD staging criteria and each pulmonary function parameter, and systemic steroid use, which

218 indicated that patients with persistent systemic inflammation had an increased need to use

219 systemic steroid to either prevent acute exacerbation or relieve the symptoms of airway

220 obstruction. These findings were in line with several previous studies. CRP was negatively

221 related to FEV1 (de Torres et al., 2008; Saetta, 1999), FEV1\% predicted (Saetta, 1999), and

222 FEV1, FVC, and arterial oxygen saturation (Dahl et al., 2007). Furthermore, Sin and Man found

223 that the negative association between CRP, and FEV1 and FVC, in COPD patients was much

224 stronger in men than in women (Sin \& Man, 2003). These findings suggest that persistent

225 systemic inflammation in COPD links worse lung condition with extra-pulmonary comorbidities

226 such as osteoporosis or general cachexia and explains why some studies revealed that poor

227 pulmonary function parameters such as FEV1 were associated with osteoporosis development

228 (Lin et al., 2015; Watanabe et al., 2015).

229 Low creatinine level was associated with osteoporosis in this study. Lower creatinine level

230 could indicate two possibilities, one was relatively better renal function, and the other was

231 relatively lower muscle mass. Serum creatinine is a metabolite of creatine phosphate, which

232 mostly originates from skeletal muscle with a stable breakdown rate. Therefore, serum creatinine

233 level directly reflects the amount of muscle mass unless renal function changes (Huh et al., 2015;

234 Kim et al., 2016). A recent study reported that low serum creatinine was related to low 
235 appendicular muscle mass and low BMD in subjects with a glomerular filtration rate $>60$

$236 \mathrm{~mL} / \mathrm{min} / 1.73 \mathrm{~m}^{2}$. Sarcopenia and osteoporosis should be considered in male and female patients

237 with creatinine levels $<0.88 \mathrm{mg} / \mathrm{dL}$ and $<0.75 \mathrm{mg} / \mathrm{dL}$, respectively (Huh et al., 2015). Loss of fat-

238 free mass was related to COPD severity and low BMD (Bolton et al., 2004). In the questionnaire

239 interivew of the present study, most COPD patients had no history of renal diseases except only

240 one COPD patient in non-osteoporotic group was reported to have chronic kidney disease (Table

241 4). And since it is well known that good renal function is not related to the development of

242 osteoporosis, the only explanation of the association between low creatinine level and

243 osteoporosis was that low muscle mass relating to the occurrence of osteoporosis. For the

244 findings, we suggest that the occurrence of sarcopenia and increased risk of osteoporosis should

245 be considered in COPD patients with low creatinine levels, although normal creatinine levels

246 should not exclude sarcopenia or chronic kidney disease because prevalences of both sarcopenia

247 and chronic kidney disease may be increased in COPD patients (Bolton et al., 2004; Chen et al.,

248 2013; Incalzi et al., 2010). In this situation, a low creatinine level would be a more sensitive

249 indicator of sarcopenia. Because measurement of creatinine is simple and inexpensive, this

250 parameter may be a useful screening tool for sarcopenia and osteoporosis in COPD patients.

251 Recently, some studies reported that increased homocysteine, decreased vitamin B12, and

252 decreased folate levels might be related to increased fracture risk or osteoporosis, although these 
253 findings remain controversial (Cagnacci et al., 2003; Fratoni \& Brandi, 2015). A study on

254 whether homocysteine, vitamin B12, and folate play roles in osteoporosis development in COPD

255 patients is still lacking. The present study included these items but did not find obvious

256 associations between them and osteoporosis in male COPD patients.

257 There were several limitations in the present study. First, the limited case number resulted in

258 insufficient statistical power for analysis of some variables. Second, this study enrolled stable

259 male COPD patients; thus, the majority of patients belonged to GOLD stages II and III, which

260 were not the group of the most severe disease with most significant inflammation. Third, certain

261 variables that might have confounded osteoporosis development, such as vitamin D deficiency,

262 were not included. Furthermore, assessments of calcium intake amount were based solely on

263 frequency of milk or calcium supplement consumption, and intensity of physical activity was

264 based on the average hours spent exercising per week or the nature of the daily employed work.

265 Differing intensity levels of different kinds of exercise or daily activity were not considered.

266 Thus, the precise role of calcium intake amount and intensity of physical activity were not

267 conclusive in this study. Moreover, recall bias might have existed in the questionnaire interview.

268 Further, this study did not include other inflammation markers such as TNF- $\alpha$, and the CRP level

269 was only measured once. There was no continuous monitoring to detect fluctuations in

270 inflammation marker level along the disease course and the effect on the pathogenesis of 
271 osteoporosis. Another limitation was the cross-sectional design of the study. Further

272 comprehensive prospective cohort studies are needed to confirm the causal relationships and

273 clarify the underlying mechanisms.

\section{Conclusions}

275 The total prevalence of osteoporosis and osteopenia in male Taiwanese COPD patients is higher

276 than that in age-matched male subjects and increased CRP level, which indicated systemic

277 inflammation is an independent risk factor for osteoporosis development. Low creatinine level in

278 COPD patients should raise the suspicion of sarcopenia and associated increased risk of

279 osteoporosis.

\section{Acknowledgment}

281 The authors are honored to acknowledge the assistance of the Chiayi County Health Bureau and

282 local public health centers.

\section{References}

284 Afonso AS, Verhamme KM, Sturkenboom MC, Brusselle GG. 2011. COPD in the general population: prevalence, incidence, and survival. Respir Med 105:1872-1884. 10.1016/j.rmed.2011.06.012

Ali T, Lam D, Bronze MS, Humphrey MB. 2009. Osteoporosis in inflammatory bowel disease. Am J Med 122:599-604. 10.1016/j.amjmed.2009.01.022

Barnes PJ, Celli BR. 2009. Systemic manifestations and comorbidities of COPD. Eur Respir J 
290

291

292

293

294

295

296

297

298

299

300

301

302

303

304

305

306

307

308

309

310

311

312

313

314

315

316

317

318

319

320

321

322

323

324

325

33:1165-1185. 10.1183/09031936.00128008

Bolton CE, Ionescu AA, Shiels KM, Pettit RJ, Edwards PH, Stone MD, Nixon LS, Evans WD, Griffiths TL, Shale DJ. 2004. Associated loss of fat-free mass and bone mineral density in chronic obstructive pulmonary disease. Am J Respir Crit Care Med 170:1286-1293. 10.1164/rccm.200406-754OC

Buess T, Ludwig C. 1995. [Diagnostic value of C-reactive protein in comparison with erythrocyte sedimentation as routine admission diagnostic test]. Schweiz Med Wochenschr 125:120124.

Cagnacci A, Baldassari F, Rivolta G, Arangino S, Volpe A. 2003. Relation of homocysteine, folate, and vitamin B12 to bone mineral density of postmenopausal women. Bone 33:956959.

Chen CY, Hsu TW, Mao SJ, Chang SC, Yang PC, Lee YC, Yang KY. 2013. Abnormal renal resistive index in patients with mild-to-moderate chronic obstructive pulmonary disease. Copd 10:216-225. 10.3109/15412555.2012.719051

Chen SJ, Liao WC, Huang KH, Lin CL, Tsai WC, Kung PT, Chang KH, Kao CH. 2015. Chronic obstructive pulmonary disease and allied conditions is a strong independent risk factor for osteoporosis and pathologic fractures: a population-based cohort study. Qjm 108:633-640. http://dx.doi.org/10.1093/qjmed/hcv012

Dahl M, Vestbo J, Lange P, Bojesen SE, Tybjaerg-Hansen A, Nordestgaard BG. 2007. C-reactive protein as a predictor of prognosis in chronic obstructive pulmonary disease. Am J Respir Crit Care Med 175:250-255. 10.1164/rccm.200605-713OC

de Torres JP, Pinto-Plata V, Casanova C, Mullerova H, Cordoba-Lanus E, Muros de Fuentes M, Aguirre-Jaime A, Celli BR. 2008. C-reactive protein levels and survival in patients with moderate to very severe COPD. Chest 133:1336-1343. 10.1378/chest.07-2433

Ekstrom MP, Jogreus C, Strom KE. 2012. Comorbidity and sex-related differences in mortality in oxygen-dependent chronic obstructive pulmonary disease. PLoS One 7:e35806. 10.1371/journal.pone.0035806

Fratoni V, Brandi ML. 2015. B vitamins, homocysteine and bone health. Nutrients 7:2176-2192. 10.3390/nu7042176

Gan WQ, Man SF, Senthilselvan A, Sin DD. 2004. Association between chronic obstructive pulmonary disease and systemic inflammation: a systematic review and a meta-analysis. Thorax 59:574-580.

Graat-Verboom L, Wouters EF, Smeenk FW, van den Borne BE, Lunde R, Spruit MA. 2009. Current status of research on osteoporosis in COPD: a systematic review. European Respiratory Journal 34:209-218.

Huh JH, Choi SI, Lim JS, Chung CH, Shin JY, Lee MY. 2015. Lower Serum Creatinine Is

PeerJ reviewing PDF | (2017:08:20097:1:0:REVIEW 13 Nov 2017) 
326

327

328

329

330

331

332

333

334

335

336

337

338

339

340

341

342

343

344

345

346

347

348

349

350

351

352

353

354

355

356

357

358

359

360

361

Associated with Low Bone Mineral Density in Subjects without Overt Nephropathy. PLoS ONE [Electronic Resource] 10:e133062.

Incalzi RA, Corsonello A, Pedone C, Battaglia S, Paglino G, Bellia V. 2010. Chronic renal failure: a neglected comorbidity of COPD. Chest 137:831-837. 10.1378/chest.09-1710

Johannessen A, Nilsen RM, Storebo M, Gulsvik A, Eagan T, Bakke P. 2013. Comparison of 2011 and 2007 Global Initiative for Chronic Obstructive Lung Disease guidelines for predicting mortality and hospitalization. Am J Respir Crit Care Med 188:51-59. 10.1164/rccm.201212-2276OC

Kanis JA, Johnell O, Oden A, Johansson H, McCloskey E. 2008. FRAX and the assessment of fracture probability in men and women from the UK. Osteoporos Int 19:385-397. 10.1007/s00198-007-0543-5

Kim SW, Jung HW, Kim CH, Kim KI, Chin HJ, Lee H. 2016. A New Equation to Estimate Muscle Mass from Creatinine and Cystatin C. PLoS ONE [Electronic Resource] 11:e0148495.

Lacativa PG, Farias ML. 2010. Osteoporosis and inflammation. Arq Bras Endocrinol Metabol 54:123-132.

Lane NE. 2006. Therapy Insight: osteoporosis and osteonecrosis in systemic lupus erythematosus. Nat Clin Pract Rheumatol 2:562-569. 10.1038/ncprheum0298

Lee PH, Kok VC, Chou PL, Ku MC, Chen YC, Horng JT. 2016. Risk and clinical predictors of osteoporotic fracture in East Asian patients with chronic obstructive pulmonary disease: a population-based cohort study. PeerJ 4:e2634. 10.7717/peerj.2634

Liang B, Feng Y. 2012. The association of low bone mineral density with systemic inflammation in clinically stable COPD. Endocrine 42:190-195. 10.1007/s12020-011-9583-x

Lin CW, Chen YY, Chen YJ, Liang CY, Lin MS, Chen W. 2015. Prevalence, risk factors, and health-related quality of life of osteoporosis in patients with COPD at a community hospital in Taiwan. International Journal of Copd 10:1493-1500. http://dx.doi.org/10.2147/COPD.S85432

Liu WT, Kuo HP, Liao TH, Chiang LL, Chen LF, Hsu MF, Chuang HC, Lee KY, Huang CD, Ho SC. 2015. Low bone mineral density in COPD patients with osteoporosis is related to low daily physical activity and high COPD assessment test scores. International Journal of Copd 10:1737-1744. http://dx.doi.org/10.2147/COPD.S87110

Loke YK, Cavallazzi R, Singh S. 2011. Risk of fractures with inhaled corticosteroids in COPD: systematic review and meta-analysis of randomised controlled trials and observational studies. Thorax 66:699-708. 10.1136/thx.2011.160028

Melton LJ, 3rd, Atkinson EJ, O'Fallon WM, Wahner HW, Riggs BL. 1993. Long-term fracture prediction by bone mineral assessed at different skeletal sites. $J$ Bone Miner Res 8:1227- 
362

363

364

365

366

367

368

369

370

371

372

373

374

375

376

377

378

379

380

381

382

383

384

385

386

387

388

389

390

391

392

393

394

1233. 10.1002/jbmr.5650081010

Murray CJ, Lopez AD. 1997. Global mortality, disability, and the contribution of risk factors: Global Burden of Disease Study. Lancet 349:1436-1442. 10.1016/S0140-6736(96)074958

Rittayamai N, Chuaychoo B, Sriwijitkamol A. 2012. Prevalence of osteoporosis and osteopenia in Thai COPD patients. J Med Assoc Thai 95:1021-1027.

Romme EA, Smeenk FW, Rutten EP, Wouters EF. 2013. Osteoporosis in chronic obstructive pulmonary disease. Expert Review of Respiratory Medicine 7:397-410.

Saetta M. 1999. Airway inflammation in chronic obstructive pulmonary disease. Am J Respir Crit Care Med 160: S17-20. 10.1164/ajrccm.160.supplement_1.6

Sambrook P, Cooper C. 2006. Osteoporosis. Lancet 367:2010-2018. 10.1016/s01406736(06)68891-0

Schnell K, Weiss CO, Lee T, Krishnan JA, Leff B, Wolff JL, Boyd C. 2012. The prevalence of clinically-relevant comorbid conditions in patients with physician-diagnosed COPD: a cross-sectional study using data from NHANES 1999-2008. BMC Pulm Med 12:26. 10.1186/1471-2466-12-26

Silva DR, Coelho AC, Dumke A, Valentini JD, de Nunes JN, Stefani CL, da Silva Mendes LF, Knorst MM. 2011. Osteoporosis prevalence and associated factors in patients with COPD: a cross-sectional study. Respir Care 56:961-968. 10.4187/respcare.01056

Sin DD, Anthonisen NR, Soriano JB, Agusti AG. 2006. Mortality in COPD: Role of comorbidities. Eur Respir J 28:1245-1257. 10.1183/09031936.00133805

Sin DD, Man SF. 2003. Why are patients with chronic obstructive pulmonary disease at increased risk of cardiovascular diseases? The potential role of systemic inflammation in chronic obstructive pulmonary disease. Circulation 107:1514-1519.

Vestbo J, Hurd SS, Agusti AG, Jones PW, Vogelmeier C, Anzueto A, Barnes PJ, Fabbri LM, Martinez FJ, Nishimura M, Stockley RA, Sin DD, Rodriguez-Roisin R. 2013. Global strategy for the diagnosis, management, and prevention of chronic obstructive pulmonary disease: GOLD executive summary. Am J Respir Crit Care Med 187:347-365. 10.1164/rccm.201204-0596PP

Watanabe R, Tanaka T, Aita K, Hagiya M, Homma T, Yokosuka K, Yamakawa H, Yarita T, Tai N, Hirano J, Inoue D, Okazaki R. 2015. Osteoporosis is highly prevalent in Japanese males with chronic obstructive pulmonary disease and is associated with deteriorated pulmonary function. J Bone Miner Metab 33:392-400. 10.1007/s00774-014-0605-7 


\section{Table 1 (on next page)}

Definition of some lifestyle habit or medical condition variables 
Table 1: Definition of some lifestyle habit or medical condition variables

\begin{tabular}{|c|c|c|c|c|}
\hline Variables & Habits/conditions & Frequency & Duration & Source \\
\hline \multirow{4}{*}{$\begin{array}{l}\text { High calcium intake (milk } \\
\text { or calcium supplement) }\end{array}$} & Habitual milk & $\geq 7$ glasses/week & $\geq 1$ year. & Questionnaire \\
\hline & consumption & & & \\
\hline & Calcium & Frequent use & $\geq 1$ year. & Questionnaire \\
\hline & supplement & & & \\
\hline High physical activity & Habitual exercise & $\geq 3.5$ hours/week & $\geq 1$ year & Questionnaire \\
\hline (habitual exercise or & Manual labor & As a job & $\geq 1$ year & Questionnaire \\
\hline \multirow{3}{*}{$\begin{array}{l}\text { COPD with acute } \\
\text { exacerbation }\end{array}$} & Yes & Any acute exacerbation & During & Medical \\
\hline & No & No any exacerbation & previous 3 & records \\
\hline & Not used & No any steroid used history* & & \\
\hline \multirow[t]{7}{*}{ Steroid use } & Occasional & Cumulative steroid use $<6$ months & During & Medical \\
\hline & Inhaled & Inhaled steroid $>6$ months in & previous 3 & records \\
\hline & & previous 3 years regardless of & years & \\
\hline & & continuously or intermittently & & \\
\hline & Oral & Oral steroid use $>6$ months in & & \\
\hline & & previous 3 years regardless of & & \\
\hline & & continuously or intermittently & & \\
\hline
\end{tabular}

Abbreviations: COPD, Chronic Obstructive Pulmonary Disease

* Note: some people did not have medical records for more than 3 years 
Table 2 (on next page)

Clinical characteristics of COPD patients and control subjects 
Table 2 Clinical characteristics of COPD patients and control subjects

\begin{tabular}{|c|c|c|c|c|c|}
\hline \multirow[t]{2}{*}{ Variables } & \multicolumn{2}{|c|}{ Control group } & \multicolumn{2}{|c|}{ COPD group } & \multirow[t]{2}{*}{$P$-value } \\
\hline & $\mathrm{n}$ & $\begin{array}{l}\text { mean } \pm S D \\
\text { percentage }\end{array}$ & $\mathrm{n}$ & $\begin{array}{l}\text { mean } \pm S D \\
\text { percentage }\end{array}$ & \\
\hline Age (years) & 36 & $71.1 \pm 5.9$ & 59 & $71.3 \pm 7.4$ & $0.846^{\mathrm{a}}$ \\
\hline Body height $(\mathrm{cm})$ & 36 & $161.4 \pm 5.3$ & 59 & $164.2 \pm 6.1$ & $0.028^{a}$ \\
\hline Body weight (kg) & 36 & $65.8 \pm 8.4$ & 59 & $63.6 \pm 11.8$ & $0.340^{\mathrm{a}}$ \\
\hline BMI $\left(\mathrm{kg} / \mathrm{m}^{2}\right)$ & 36 & $25.2 \pm 3.0$ & 59 & $23.6 \pm 4.1$ & $0.035^{\mathrm{a}}$ \\
\hline L spine BMD $\left(\mathrm{g} / \mathrm{cm}^{2}\right)$ & 35 & $1.03 \pm 0.21$ & 58 & $0.94 \pm 0.19$ & $0.054^{\mathrm{a}}$ \\
\hline Hip BMD $\left(\mathrm{g} / \mathrm{cm}^{2}\right)$ & 36 & $0.92 \pm 0.13$ & 57 & $0.84 \pm 0.14 \mathrm{~S}$ & $0.011^{\mathrm{a}}$ \\
\hline Smoking & 36 & & 59 & & $0.001^{\mathrm{b}}$ \\
\hline no smoking & & $69.4 \%(25 / 36)$ & & $28.8 \%(17 / 59)$ & \\
\hline quit & & $13.9 \%(5 / 36)$ & & $39.0 \%(23 / 59)$ & \\
\hline still smoking & & $16.7 \%(6 / 36)$ & & $32.2 \%(19 / 59)$ & \\
\hline High physical activity & 36 & $63.9 \%(23 / 36)$ & 59 & $52.5 \%(31 / 59)$ & $0.279^{b}$ \\
\hline \multicolumn{6}{|l|}{ Comorbidity } \\
\hline Hypertension & 36 & $38.9 \%(14 / 36)$ & 59 & $33.9 \%(20 / 59)$ & $0.623^{b}$ \\
\hline Diabetes mellitus & 36 & $2.8 \%(1 / 36)$ & 59 & $5.1 \%(3 / 59)$ & $1.000^{c}$ \\
\hline Dyslipidemia & 36 & $11.1 \%(4 / 36)$ & 59 & $8.5 \%(5 / 59)$ & $0.726^{c}$ \\
\hline Chronic kidney disease & 36 & $2.8 \%(1 / 36)$ & 59 & $1.7 \%(1 / 59)$ & $1.000^{c}$ \\
\hline Chronic hepatitis & 36 & $2.8 \%(1 / 36)$ & 58 & $1.7 \%(1 / 58)$ & $1.000^{c}$ \\
\hline
\end{tabular}

Abbreviations: BMD, bone mineral density; BMI, body mass index; SD, standard deviation

${ }^{\text {a }} P$-value by independent sample t-test.

${ }^{\text {b }} P$-value by Chi-square test.

${ }^{c} P$-value by Fisher's exact test. 


\section{Table 3(on next page)}

Binary logistic regression for multivariate analysis for the risk of increased prevalence of osteoporosis and osteopenia in COPD and healthy control subjects 
Table 3 Binary logistic regression for multivariate analysis for the risk of increased prevalence of osteoporosis and osteopenia in COPD and healthy control subjects

\begin{tabular}{|c|c|c|c|c|c|c|}
\hline \multirow[t]{2}{*}{ Variables } & \multirow[t]{2}{*}{ B } & \multirow[t]{2}{*}{ SE } & \multirow{2}{*}{$\begin{array}{l}\text { Odds } \\
\text { ratio }\end{array}$} & \multicolumn{2}{|c|}{$95 \% \mathrm{Cl}$} & \multirow[t]{2}{*}{$P$-value } \\
\hline & & & & Lower & Upper & \\
\hline Age (years) & -0.003 & 0.038 & 1.00 & 0.93 & 1.07 & 0.938 \\
\hline BMI $\left(\mathrm{kg} / \mathrm{m}^{2}\right)$ & -0.229 & 0.080 & 0.80 & 0.68 & 0.93 & 0.004 \\
\hline COPD & 0.631 & 0.506 & 1.88 & 0.70 & 5.07 & 0.213 \\
\hline $\mathrm{hs}-\mathrm{CRP} \geq 5$ (mg/L) & 1.724 & 1.198 & 5.61 & 0.54 & 58.71 & 0.150 \\
\hline Creatinine & -0.767 & 1.017 & 0.46 & 0.006 & 3.41 & 0.451 \\
\hline Still smoking & -0.177 & 0.613 & 0.84 & 0.25 & 2.79 & 0.838 \\
\hline Milk/Calcium supplement & 0.062 & 0.507 & 1.06 & 0.39 & 2.88 & 0.902 \\
\hline Hight physical acitivity & -0.187 & 0.521 & 0.83 & 0.30 & 2.30 & 0.719 \\
\hline Constant & 6.789 & 3.712 & 887.80 & & & 0.067 \\
\hline
\end{tabular}

Abbreviations: BMI, body mass index; COPD, chronic obstructive pulmonary disease; hs-CRP, hypersensitive C-reactive protein; FEV1, forced expiratory volume in one second; $\mathrm{Cl}$, confidence interval; 


\section{Table 4(on next page)}

Clinical characteristics and laboratory test of COPD patients with and without osteoporosis 
Table 4 Clinical characteristics and laboratory test of COPD patients with and without osteoporosis

\begin{tabular}{|c|c|c|c|c|c|}
\hline \multirow[t]{2}{*}{ Variables } & \multicolumn{2}{|r|}{ Non-osteoporosis group } & \multicolumn{2}{|r|}{ Osteoporosis group } & \multirow[t]{2}{*}{$P$-value } \\
\hline & $\mathrm{n}$ & $\begin{array}{l}\text { mean } \pm S D \\
\text { percentage }\end{array}$ & $\mathrm{n}$ & $\begin{array}{l}\text { mean } \pm S D \\
\text { percentage }\end{array}$ & \\
\hline Age (years) & 42 & $70.8 \pm 7.2$ & 17 & $72.8 \pm 8.2$ & $0.354^{\mathrm{a}}$ \\
\hline L spine BMD $\left(\mathrm{g} / \mathrm{cm}^{2}\right)$ & 41 & $1.02 \pm 0.16$ & 17 & $0.76 \pm 0.10$ & $<0.001^{\mathrm{a}}$ \\
\hline Hip BMD $\left(\mathrm{g} / \mathrm{cm}^{2}\right)$ & 41 & $0.89 \pm 0.12$ & 16 & $0.72 \pm 0.11$ & $<0.001^{a}$ \\
\hline \multicolumn{6}{|l|}{ Anthropometric data } \\
\hline Body height $(\mathrm{cm})$ & 42 & $164.0 \pm 6.3$ & 17 & $164.7 \pm 6.0$ & $0.664^{\mathrm{a}}$ \\
\hline Body weight (kg) & 42 & $65.7 \pm 11.8$ & 17 & $58.4 \pm 10.5$ & $0.030^{\mathrm{a}}$ \\
\hline $\mathrm{BMI}\left(\mathrm{kg} / \mathrm{m}^{2}\right)$ & 42 & $24.4 \pm 4.1$ & 17 & $21.4 \pm 3.2$ & $0.009^{\mathrm{a}}$ \\
\hline Waist circumflex $(\mathrm{cm})$ & 39 & $91.1 \pm 11.7$ & 16 & $83.2 \pm 10.4$ & $0.024^{a}$ \\
\hline Hip circumflex (cm) & 38 & $94.1 \pm 7.1$ & 16 & $91.3 \pm 6.1$ & $0.174^{\mathrm{a}}$ \\
\hline \multicolumn{6}{|l|}{ Laboratory test } \\
\hline Bun (mg/dL) & 37 & $16.9 \pm 5.1$ & 14 & $15.7 \pm 6.0$ & $0.497^{\mathrm{a}}$ \\
\hline Creatinine $(\mathrm{mg} / \mathrm{dL})$ & 39 & $1.2 \pm 0.3$ & 14 & $1.0 \pm 0.2$ & $0.050^{\mathrm{a}}$ \\
\hline Cholesterol (mg/dL) & 38 & $188.8 \pm 35.1$ & 14 & $184.0 \pm 29.0$ & $0.651^{\mathrm{a}}$ \\
\hline $\mathrm{HDL}(\mathrm{mg} / \mathrm{dL})$ & 38 & $52.6 \pm 14.0$ & 14 & $53.9 \pm 11.1$ & $0.765^{\mathrm{a}}$ \\
\hline LDL (mg/dL) & 38 & $120.8 \pm 30.6$ & 14 & $119.6 \pm 31.3$ & $0.901^{\mathrm{a}}$ \\
\hline Triglyceride (mg/dL) & 38 & $112.9 \pm 61.6$ & 14 & $79.9 \pm 18.9$ & $0.005^{\mathrm{a}}$ \\
\hline HbA1c (\%) & 37 & $5.9 \pm 0.9$ & 14 & $5.7 \pm 0.3$ & $0.372^{\mathrm{a}}$ \\
\hline Uric acid (mg/dL) & 38 & $6.8 \pm 1.6$ & 14 & $6.3 \pm 1.3$ & $0.311^{\mathrm{a}}$ \\
\hline Homocysteine (umol/L) & 42 & $17.5 \pm 21.7$ & 17 & $12.6 \pm 3.3$ & $0.358^{\mathrm{a}}$ \\
\hline Vitamin B12 (pg/mL) & 42 & $628.6 \pm 287.1$ & 17 & $713.8 \pm 413.8$ & $0.370^{\mathrm{a}}$ \\
\hline Folate $(\mathrm{ng} / \mathrm{mL})$ & 40 & $11.5 \pm 7.3$ & 17 & $9.8 \pm 3.9$ & $0.363^{\mathrm{a}}$ \\
\hline hs-CRP (mg/L); ( $\geq 5(\mathrm{mg} / \mathrm{L}))$ & 41 & $\begin{array}{l}2.60 \pm 3.58 ; 7.3 \% \\
(3 / 41)\end{array}$ & 16 & $\begin{array}{l}22.63 \pm 47.06 ; 31.3 \% \\
(5 / 16)\end{array}$ & $0.109^{\mathrm{a}} ; 0.032^{\mathrm{c}}$ \\
\hline Milk/Calcium supplement & 42 & $40.5 \%(17 / 42)$ & 17 & $35.3 \%(6 / 17)$ & $0.712^{b}$ \\
\hline High physical activity & 42 & $47.6 \%(20 / 42)$ & 17 & $64.7 \%(11 / 17)$ & $0.234^{b}$ \\
\hline \multicolumn{6}{|l|}{ Comorbidity } \\
\hline Hypertension & 42 & $35.7 \%(15 / 42)$ & 17 & $29.4 \%(5 / 17)$ & $0.643^{b}$ \\
\hline Diabetes mellitus & 42 & $7.1 \%(3 / 42)$ & 17 & $0(0 / 17)$ & $0.550^{c}$ \\
\hline Dyslipidemia & 42 & $33.3 \%(4 / 42)$ & 17 & $5.9 \%(1 / 17)$ & $1.000^{c}$ \\
\hline Chronic kidney disease & 42 & $2.4 \%(1 / 42)$ & 17 & $0(0 / 17)$ & $1.000^{c}$ \\
\hline Chronic hepatitis & 41 & $2.4 \%(1 / 41)$ & 17 & $0(0 / 17)$ & $1.000^{c}$ \\
\hline
\end{tabular}

Abbreviations: BMD, bone mineral density; BMI, body mass index; HDL, high density 
lipoprotein; LDL, low density lipoprotein; SD, standard deviation

${ }^{\text {a }} P$-value by independent sample t-test.

${ }^{\mathrm{b}} P$-value by Chi-square test.

${ }^{c} P$-value by Fisher's exact test. 


\section{Table 5 (on next page)}

Comparison of COPD patients with high and low hypersensitive C-reactive protein level 
Table 5 Comparison of COPD patients with high and low hypersensitive C-reactive protein level

\begin{tabular}{|c|c|c|c|c|c|}
\hline \multirow[t]{2}{*}{ Variables } & \multicolumn{2}{|c|}{ hs-CRP < 5 (mg/L) } & \multicolumn{2}{|r|}{$\mathrm{hs}-\mathrm{CRP} \geq 5(\mathrm{mg} / \mathrm{L})$} & \multirow[t]{2}{*}{$P$-value } \\
\hline & $\mathrm{N}$ & $\begin{array}{l}\text { mean } \pm S D \\
\text { percentage }\end{array}$ & $\mathrm{n}$ & $\begin{array}{l}\text { mean } \pm S D \\
\text { percentage }\end{array}$ & \\
\hline Age (years) & 49 & $71.0 \pm 7.4$ & 8 & $71.0 \pm 7.3$ & $0.988^{\mathrm{a}}$ \\
\hline BMI & 49 & $24.0 \pm 4.1$ & 8 & $21.4 \pm 3.5$ & $0.092^{\mathrm{a}}$ \\
\hline COPD GOLD stage & 49 & & 8 & & $0.023^{b}$ \\
\hline Stage I & & $14.3 \%(7 / 49)$ & & $0(0 / 8)$ & \\
\hline Stage II & & $20.8 \%(20 / 49)$ & & $25 \%(2 / 8)$ & \\
\hline Stage III & & $42.9 \%(21 / 49)$ & & $37.5 \%(3 / 8)$ & \\
\hline Stage IV & & $2.0 \%(1 / 49)$ & & $37.5 \%(3 / 8)$ & \\
\hline \multicolumn{6}{|l|}{ Pulmonary function test } \\
\hline FEV1 (L) & 49 & $1.36 \pm 0.44$ & 8 & $0.78 \pm 0.33$ & $0.001^{a}$ \\
\hline FEV1\% predicted (\%) & 49 & $54.4 \pm 17.4$ & 8 & $34.1 \pm 14.4$ & $0.003^{a}$ \\
\hline FVC (L) & 49 & $2.16 \pm 0.60$ & 8 & $1.40 \pm 0.41$ & $0.001^{a}$ \\
\hline FVC\% predicted (\%) & 49 & $67.8 \pm 16.7$ & 8 & $50.1 \pm 20.8$ & $0.010^{a}$ \\
\hline FEV1/FVC (\%) & 49 & $62.4 \pm 8.8$ & 8 & $54.3 \pm 10.3$ & $0.022^{a}$ \\
\hline FEV25-75 (\%) & 49 & $32.7 \pm 14.2$ & 8 & $17.9 \pm 7.7$ & $0.000^{\mathrm{a}}$ \\
\hline Smoking & 49 & & 8 & & $0.165^{b}$ \\
\hline No smoking & & $30.6 \%(15 / 49)$ & & $12.5 \%(1 / 8)$ & \\
\hline Quit & & $34.7 \%(17 / 49)$ & & $75.0 \%(6 / 8)$ & \\
\hline Still smoking & & $34.7 \%(17 / 49)$ & & $12.5 \%(1 / 8)$ & \\
\hline Acute exacerbation & 43 & $30.2 \%(13 / 43)$ & 8 & $62.5 \%(5 / 8)$ & $0.112^{\mathrm{c}}$ \\
\hline Steroid used & 49 & & 8 & & $0.005^{\mathrm{b}}$ \\
\hline No steroid used & & $44.9 \%(22 / 49)$ & & $0(0 / 8)$ & \\
\hline Occasional & & $12.2 \%(6 / 49)$ & & $12.5 \%(1 / 8)$ & \\
\hline Inhaled & & $34.7 \%(17 / 49)$ & & $37.5 \%(3 / 8)$ & \\
\hline Systemic & & $8.2 \%(4 / 49)$ & & $50 \%(4 / 8)$ & \\
\hline
\end{tabular}

Abbreviations: hs-CRP, hypersensitive C-reactive protein; GOLD, global Initiative for Chronic Obstructive lung Disease; FEV1, forced expiratory volume in one second; FEV1\% predicted, forced expiratory volume in one second of predicted value; FVC, forced vital capacity; FVC\% predicted, forced vital capacity of predicted value; FEF 2575, forced expiratory flow $25-75 \%$;

${ }^{\text {a }} P$-value by independent sample t-test.

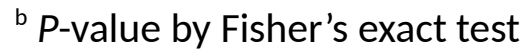

${ }^{\mathrm{c}} P$-value by $\mathrm{Chi}$-square test. 


\section{Table 6(on next page)}

COPD related factors in patients with and without osteoporosis 
Table 6 COPD related factors in patients with and without osteoporosis

\begin{tabular}{|c|c|c|c|c|c|}
\hline \multirow[t]{2}{*}{ Variables } & \multicolumn{2}{|r|}{ Non-osteoporosis group } & \multicolumn{2}{|r|}{ Osteoporosis group } & \multirow[t]{2}{*}{$P$-value } \\
\hline & $\mathrm{N}$ & $\begin{array}{l}\text { mean } \pm S D \\
\text { percentage }\end{array}$ & $\mathrm{n}$ & $\begin{array}{l}\text { mean } \pm S D \\
\text { percentage }\end{array}$ & \\
\hline COPD GOLD stage & 42 & & 17 & & $0.271^{\mathrm{a}}$ \\
\hline Stage I & & $16.7 \%(7 / 42)$ & & $0(0 / 17)$ & \\
\hline Stage II & & $33.3 \%(14 / 42)$ & & $52.9 \%(9 / 17)$ & \\
\hline Stage III & & $42.9 \%(18 / 42)$ & & $41.2 \%(7 / 17)$ & \\
\hline Stage IV & & $7.1 \%(3 / 42)$ & & $5.9 \%(1 / 17)$ & \\
\hline \multicolumn{6}{|c|}{ Pulmonary function test } \\
\hline FEV1 (L) & 42 & $1.29 \pm 0.49$ & 17 & $1.18 \pm 0.44$ & $0.428^{b}$ \\
\hline FEV1\% predicted (\%) & 42 & $53.1 \pm 19.4$ & 17 & $47.8 \pm 13.8$ & $0.313^{b}$ \\
\hline FVC (L) & 42 & $2.06 \pm 0.67$ & 17 & $1.97 \pm 0.53$ & $0.619^{b}$ \\
\hline FVC\% predicted (\%) & 42 & $66.4 \pm 19.0$ & 17 & $63.5 \pm 15.7$ & $0.589^{b}$ \\
\hline FEV1/FVC (\%) & 42 & $62.0 \pm 9.2$ & 17 & $58.8 \pm 9.5$ & $0.233^{b}$ \\
\hline FEF $25-75$ (\%) & 42 & $31.6 \pm 15.1$ & 17 & $27.3 \pm 11.5$ & $0.294^{b}$ \\
\hline Smoking & 42 & & 17 & & $0.956^{c}$ \\
\hline No smoking & & $28.6 \%(12 / 42)$ & & $29.4 \%(5 / 17)$ & \\
\hline Quit & & $38.1 \%(16 / 42)$ & & $41.2 \%(7 / 17)$ & \\
\hline Still smoking & & $33.3 \%(14 / 42)$ & & $29.4 \%(5 / 17)$ & \\
\hline Acute exacerbation & 37 & $32.4 \%(12 / 37)$ & 16 & $43.8 \%(7 / 16)$ & $0.430^{c}$ \\
\hline Steroid used & 42 & & 17 & & $0.946^{\mathrm{a}}$ \\
\hline Oral & & $11.9 \%(5 / 42)$ & & $17.6 \%(3 / 17)$ & \\
\hline Inhaled & & $38.1 \%(16 / 42)$ & & $35.3 \%(6 / 17)$ & \\
\hline Occasional & & $11.9 \%(5 / 42)$ & & $11.8 \%(2 / 17)$ & \\
\hline No steroid used & & $38.1 \%(16 / 42)$ & & $35.3 \%(6 / 17)$ & \\
\hline
\end{tabular}

Abbreviations: GOLD, global Initiative for Chronic Obstructive lung Disease; FEV1, forced expiratory volume in one second; FEV1\% predicted, forced expiratory volume in one second of predicted value; FVC, forced vital capacity; FVC\% predicted, forced vital capacity of predicted value; FEF 25-75, forced expiratory flow 25-75\%; hs-CRP, hypersensitive $\mathrm{C}$-reactive protein, SD, standard deviation

${ }^{\text {a }} P$-value by Fisher's exact test.

${ }^{b} P$-value by independent sample t-test.

${ }^{\mathrm{c}} P$-value by Chi-square test. 


\section{Table 7 (on next page)}

Binary logistic regression for multivariate analysis of osteoporosis risk factors in COPD patients 
Table 7 Binary logistic regression for multivariate analysis of osteoporosis risk factors in COPD patients.

\begin{tabular}{|c|c|c|c|c|c|c|}
\hline \multirow{2}{*}{ Variables } & \multirow[t]{2}{*}{ B } & \multirow{2}{*}{ SE } & \multirow{2}{*}{$\begin{array}{l}\text { Odds } \\
\text { ratio }\end{array}$} & \multicolumn{2}{|c|}{$95 \% \mathrm{Cl}$} & \multirow[t]{2}{*}{$P$-value } \\
\hline & & & & Lower & Upper & \\
\hline Age (years) & 0.076 & 0.077 & 1.08 & 0.93 & 1.26 & 0.322 \\
\hline $\mathrm{BMI}\left(\mathrm{kg} / \mathrm{m}^{2}\right)$ & -0.276 & 0.157 & 0.76 & 0.56 & 1.03 & 0.079 \\
\hline $\mathrm{hs}-\mathrm{CRP} \geq 5(\mathrm{mg} / \mathrm{L})$ & 4.041 & 1.686 & 58.90 & 2.09 & 1548.13 & 0.017 \\
\hline Creatinine & -4.781 & 2.233 & 0.01 & 0.00 & 0.67 & 0.032 \\
\hline Still smoking & 1.324 & 1.015 & 3.76 & 0.51 & 27.49 & 0.192 \\
\hline Oral or inhaled steroid $>6$ & -1.570 & 1.423 & 0.21 & 0.01 & 3.39 & 0.270 \\
\hline \multicolumn{7}{|l|}{ months } \\
\hline FEV1 & 0.458 & 1.455 & 1.58 & 0.09 & 27.37 & 0.753 \\
\hline Constant & 3.733 & 8.196 & 41.82 & & & 0.649 \\
\hline
\end{tabular}

Abbreviations: BMI, body mass index; hs-CRP, hypersensitive C-reactive protein; FEV1, forced expiratory volume in one second; $\mathrm{Cl}$, confidence interval; 